Corresponding Author:

Essam M. Janahi

Received: 18 September 2018

Accepted: 10 October 2018

Published: 15 October 2018

Publishing services provided by Knowledge $\mathrm{E}$

(c) Essam M. Janahi et al. This article is distributed under the terms of the Creative Commons

Attribution License, which

permits unrestricted use and redistribution provided that the original author and source are credited.

Selection and Peer-review under the responsibility of the Sustainability and Resilience Conference Committee.

\section{Perceptions and Attitudes Towards HIV/AIDS Patients among General Public in Bahrain}

\section{Essam M. Janahi, Sakina Mustafa ${ }^{1}$, Sajeda Alsari", Mariam Al-Mannai², and Ghada N. Farhat ${ }^{3}$}

1Department of Biology, College of Science, University of Bahrain, Sakhir, Kingdom of Bahrain ${ }^{2}$ Department of Mathematics, College of Science, University of Bahrain, Sakhir, Kingdom of Bahrain

${ }^{3}$ Hubert Department of Global Health, Rollins School of Public Health, Emory University, GA 30322, United States of America

\section{Abstract}

Introduction: HIV/AIDS is a major global health problem. In Bahrain, although the prevalence of HIV is low, awareness programs are of high importance for controlling and preventing the distribution of HIV infection. The aim of this study is to determine the attitudes and risk perceptions toward HIV/AIDS in Bahrain. Results of this study will provide background knowledge to inform existing and new educational and preventive programs.

Methodology: A self-administered questionnaire-based survey was conducted among 1038 Bahraini adults.

Results: The study showed varied attitudes toward HIV/AIDS, but mostly were negative, as $60 \%$ of participants agreed to isolate HIV/AIDS patients in workplaces and schools, and $52.4 \%$ of them believed that HIV is a divine punishment. A high proportion of respondents $(84.4 \%)$ believed that religion plays an important role in minimizing the spread of the disease.

Conclusions: The Bahraini public negative attitudes toward HIV/AIDS was a major finding of this study. Successful control programs of HIV infection require limiting the negative attitudes toward HIV patients and the disease. Those negative attitudes found in this study need to be addressed through new and the currently existing education and health awareness programs in Bahrain.

Keywords: HIV/AIDS, Public Attitudes, Stigmatization, Bahrain

\section{Introduction}

One of the most serious health problems around the world is the infection with Human Immunodeficiency Virus (HIV) which causes Acquired Immunodeficiency Syndrome (AIDS), the fourth leading cause of death worldwide [1-3]. Millions of new cases are 
emerging since it was first discovered in 1980s, and many efforts are being done to lower the risk of infection and mortality rates, through development of antiviral drugs and modern genetic technologies to eliminate the virus from infected bodies [4].

Once HIV infects the human body, it attacks the CD4 cells, damaging the immune system and developing a combination of serious diseases, collectively form AIDS, including several opportunistic infections and cancers, such as pneumonia, lymphoma, Kaposi's sarcoma, and AIDS dementia [1]. The main modes of HIV transmission are still the sexual and drug-related methods among the recent infections. In many developing countries, vertical HIV transmission from mother to child is noticeably reduced with the use of antiretroviral therapy [5]. Health care associated transmission of HIV, including blood transfusion, accidental health care procedures by health workers, and unsafe injections, is another mode of the virus transmission, mainly because of the inadequate awareness about the safe practices that prevent the virus distribution, specifically in the developing countries in the first decades of the epidemic, where the injection equipment and blood contaminated stuff were commonly and unsafely reused [3].

In the regions of Middle East and North Africa, UNAIDS estimations of HIV positive cases reached 500000, with steady increase in number [5]. In kingdom of Bahrain, although there is shortage in data on HIV, the prevalence is considered very low, from less than $0.1 \%$ among general population at low risk (blood donors and antenatal care women), to $3.3-4.6 \%$ among population groups at high risk (drug users), with increase in cases from heterosexual transmission, indicating the spread of the epidemic among the community [6].

One of the key instrumental methods to control the spread of the disease is the education and awareness programs regarding HIV/AIDS $[7,8]$. They are important to lower the excessive concerns and fear from the disease specifically in low prevalence regions such as Bahrain $[9,10]$. Successful efforts of disease control requires understanding the distribution of the different health behaviors among the population, and measuring the knowledge and attitudes of the public in regards to HIV infection and patients [11-15]. Therefore, the aim of this study is to determine the practices and preventive behaviors, their risk perceptions and attitudes towards HIV/AIDS, in association with socio-demographic factors. The study findings would help in providing information for the awareness programs carried out for controlling HIV/AIDS. 


\section{Methodology}

\subsection{Study design, population and data collection}

A cross sectional survey was held in the period from September 2014 to December 2014 in the Kingdom of Bahrain. Based on a literature review, a self-administered 50-items questionnaire was prepared by authors. The study population was Bahraini adults aged 18 or older, with no foreign population included in the study. A pilot survey was run on a 50 participant's sample. Some questions were rephrased and modified according to the pilot survey results. Cronbach alpha coefficient was used for computing the questionnaire internal consistency. Results ranged from 0.72 to 0.83 with an average of 0.78 .

The questionnaire involved the participants' general socio-demographic characteristics and questions about perceptions and concerns towards HIV/AIDS, and perceptions of the Bahraini Government agencies and organizations efforts regarding HIV/AIDS. A five point Likert scale was used to indicate the answers of the participants ( $1=$ I do not know, $2=$ strongly disagree, 3 = disagree, $4=$ agree and 5= strongly agree).

Both English and Arabic versions of the questionnaire were used for a total of 1630 participants. This sample size (1630 participants) was calculated according to the 2010 Bahrain's census data [16] with 95\% confidence level and $\pm 3 \%$ sampling error, considering the total Bahraini population size is 568,399 . To ensure the demographical representation of the respondents to the general population, a systematic proportional quota sampling was applied, with quotas based on age, sex, and education level. The distribution of the hard copy of the questionnaire was done in public places in different regions of Kingdom of Bahrain, as well as a soft copy, which was sent by emails. The instructions of filling the questionnaire and the purpose of the study was clarified for the participants, in addition, they were advised not to ask for external help in order to get a more accurate idea about the degree of public awareness.

\subsection{Statistical analysis}

Data cleaning was performed by excluding the questionnaires done by non-Bahraini respondents and the incomplete questionnaires, those of more than three unanswered statements. Data then were analyzed using SPSS (version 21). Descriptive statistics ( $N$, $\%$ and mean \pm Standard Deviation [SD]) were carried out to determine the attitudes and practices of the sample. T-test or ANOVA were used for continuous variables, and 
chi square test for categorical variables, to analyze the association of these factors with gender, age, marital status, educational level, and employment status.

\subsection{Ethical issues}

This study was approved by University of Bahrain, head of Department of Biology and selected ethical committee. It conformed to the provisions of the Declaration of Helsinki in 1995 (and revised in Edinburgh 2000). All respondents signed the approval form before participation.

\section{Results}

\subsection{Response rate}

A total of 1286 questionnaires were returned out of the 1630 questionnaires distributed, (response rate $=78.9 \%$ ), and out of which 1038 were complete (complete response rate $=80.71 \%)$.

\subsection{The socio-demographic characteristics of the participants}

The mean age of the study population was of 31 years, involving $43 \%$ males and $57 \%$ females. From the participants, $38.3 \%$ had a bachelor degree, $37.9 \%$ had school certificates, and the post-graduate education had a lower percentage (Table 1). In terms of age, gender, and educational level, there were no statistically significant difference between the study population and Bahrain's recent census data [16].

\subsection{Participants' attitudes, opinions, and risk perception about HIV/AIDS}

In general, mostly negative attitudes towards HIV/AIDS were expressed by the participants. For example, $77.5 \%$ of the participants agreed that they would avoid eating food if it was made by an HIV patient, more than $50 \%$ said that they won't shake hands or sit close to the patient. In addition, $82.9 \%$ of the participants believed that HIV patients should inform their colleagues about their illness, and 60.1\% approved isolating them in schools and workplaces. Furthermore, $52.4 \%$ of the participants believed that HIV infection is considered a divine punishment. However, $65.8 \%$ of the participants felt 
TABLE 1: The Participants' socio-demographic characteristics.

\begin{tabular}{|c|c|c|c|}
\hline \multicolumn{2}{|c|}{ Variables } & \multirow[t]{2}{*}{ Frequency } & \multirow[t]{2}{*}{ Percentage (\%) } \\
\hline Gender & & & \\
\hline & Male & 446 & 43 \\
\hline & Female & 592 & 57 \\
\hline \multicolumn{4}{|l|}{ Age } \\
\hline & $<20$ & 198 & 19.1 \\
\hline & $21-30$ & 422 & 40.7 \\
\hline & $31-40$ & 238 & 22.9 \\
\hline & $41-50$ & 126 & 12.1 \\
\hline & $>51$ & 54 & 5.2 \\
\hline \multicolumn{4}{|c|}{ Marital status } \\
\hline & Single & 465 & 44.8 \\
\hline & Married & 573 & 55.2 \\
\hline \multicolumn{4}{|c|}{ Educational level } \\
\hline & School level & 393 & 37.9 \\
\hline & Diploma & 176 & 17 \\
\hline & Bachelors & 398 & 38.3 \\
\hline & Post graduates & 71 & 6.8 \\
\hline \multicolumn{4}{|c|}{ Employment status } \\
\hline & Employed & 572 & 55.1 \\
\hline & Unemployed & 182 & 17.5 \\
\hline & Students & 284 & 27.4 \\
\hline
\end{tabular}

compassionate toward HIV patients, in addition of other feelings reported like hatred, apathy fear, sadness, and cautiousness. In addition, more than 50\% agreed that HIV patients deserve a similar support and deserve as other diseases patients. More positive attitudes were expressed by married participants with only school level education than those of higher education levels and singles $(P<0.05)$. No statistically significant differences of attitudes between genders and different age categories were found (Table 2, Figure 1).

TABLE 2: P-values of participants' attitudes and opinions towards HIV patients and the disease.

Variables
Gender
Age
Marital status
Educational level
Employment
status

P value of the participants
attitudes towards HIV patients
0.470
0.609
0.000
0.012
0.103

$P$ value of the participants attitudes towards HIV disease

0.000
0.048
0.005
0.381
0.001




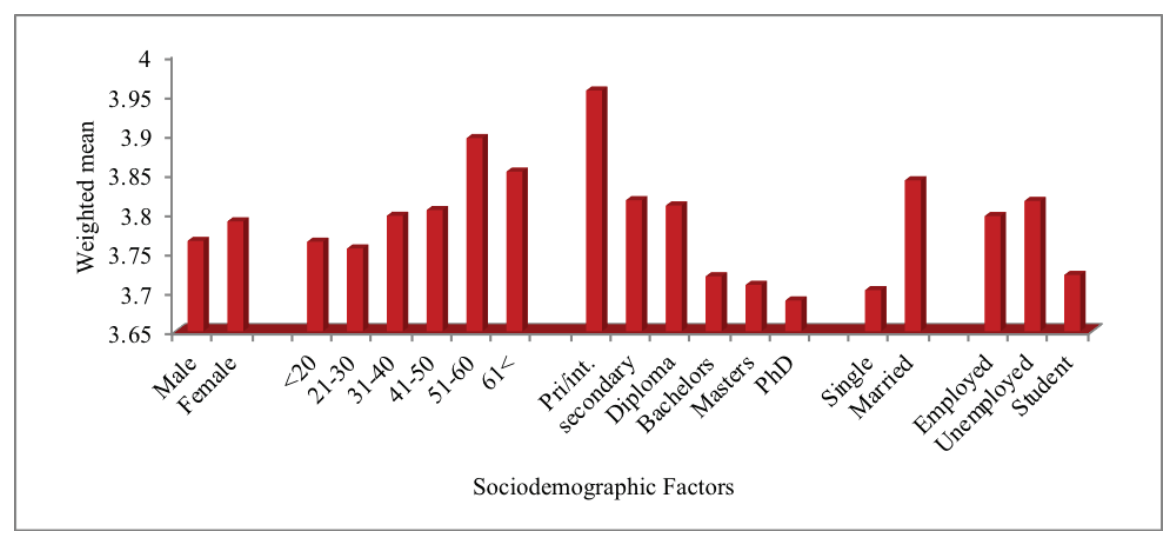

Figure 1: Participants' attitudes and opinions towards HIV/AIDS patients.

Regarding the participants' worries and threat perceptions toward HIV/AIDS epidemic, more than $59.1 \%$ of the participants believed that in the next 10 years, the number of HIV cases in Bahrain will have a sharp increase, and about $80.2 \%$ of them agreed that AIDS could become a threat to Bahraini society. More than half of the participants (54.5\%) appropriately identified that the incidence of HIV in Bahrain is low, and that the drug users cover half of cases. About $77 \%$ of the participants informed they were never tested HIV, and $68.6 \%$ of them showed no concern from getting HIV. Compared to other groups, married, male and employed participants who are aged above 50 showed a considerably higher concern of contracting HIV/AIDS (Table 2, Figure 2).

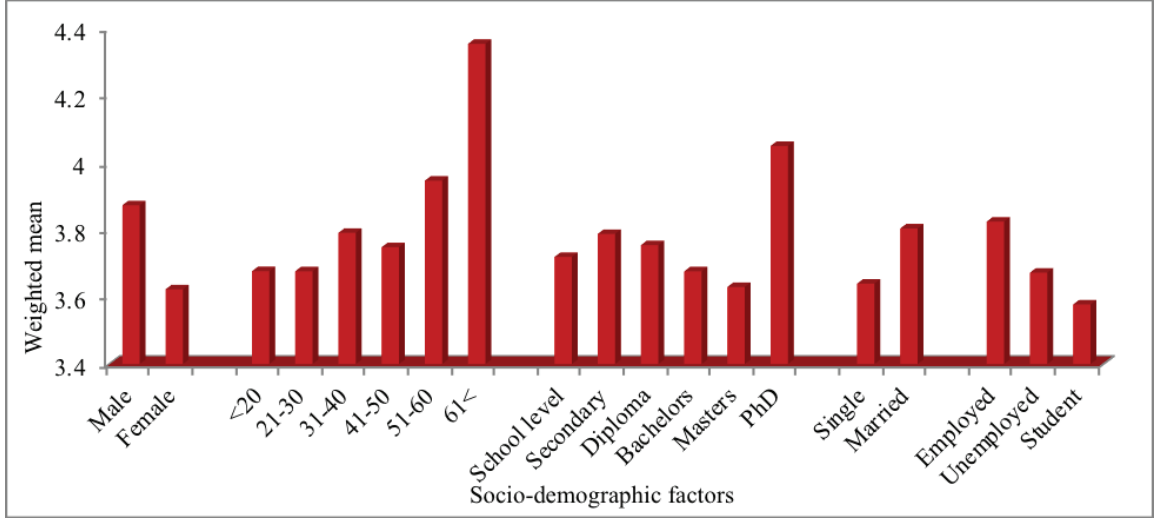

Figure 2: Participants' attitudes and opinions towards HIV disease.

Most of the participants $(84.4 \%)$ thought that following the Islamic doctrines through avoiding homosexuality, drug abuse and premarital sex will lower the distribution of HIV infection. Of all participants, about $49.9 \%$ were distrustful about whether male circumcision would play a role in reduction of HIV transmission. Comparing to other groups in regards to religious beliefs; married, male and employed participants who are aged between 41 and 50 strongly believed in the role of religious beliefs 
$(\mathrm{P}<0.05)$, although in terms of educational level, there was no statistical difference (Table 3).

TABLE 3: Participants' opinion on religious beliefs about HIV/AIDS.

\begin{tabular}{|c|c|c|c|c|c|}
\hline \multicolumn{2}{|l|}{ Variables } & \multirow{2}{*}{$\begin{array}{l}\text { Mean } \\
4.00\end{array}$} & \multirow{2}{*}{$\begin{array}{c}\text { SD } \\
0.91\end{array}$} & \multirow{2}{*}{$\begin{array}{c}95 \% \mathrm{Cl} \\
3.91-4.08\end{array}$} & \multirow{2}{*}{$\begin{array}{l}P \text { value } \\
0.000\end{array}$} \\
\hline Gender & Male & & & & \\
\hline & Female & 3.79 & 0.94 & $3.71-3.86$ & \\
\hline \multirow[t]{5}{*}{ Age } & $<20$ & 3.75 & 0.98 & $3.61-3.89$ & 0.001 \\
\hline & $21-30$ & 3.78 & 0.95 & $3.69-3.88$ & \\
\hline & $31-40$ & 3.98 & 0.87 & $3.87-4.09$ & \\
\hline & $41-50$ & 4.10 & 0.87 & $3.94-4.25$ & \\
\hline & $>51$ & 4.07 & 0.92 & $3.63-4.51$ & \\
\hline \multirow[t]{2}{*}{ Marital status } & Single & 3.78 & 0.96 & $3.69-3.87$ & 0.003 \\
\hline & Married & 3.95 & 0.90 & $3.88-4.03$ & \\
\hline \multirow[t]{4}{*}{ Educational level } & School level & 3.97 & 0.93 & $3.80-4.13$ & 0.114 \\
\hline & Diploma & 3.85 & 0.96 & $3.71-4.00$ & \\
\hline & Bachelors & 3.88 & 0.90 & $3.80-3.97$ & \\
\hline & Post graduates & 4.02 & 0.80 & $3.71-4.33$ & \\
\hline \multirow{3}{*}{$\begin{array}{l}\text { Employment } \\
\text { status }\end{array}$} & Employed & 3.94 & 0.89 & $3.87-4.01$ & 0.027 \\
\hline & Unemployed & 3.86 & 0.96 & $3.72-4.00$ & \\
\hline & Students & 3.76 & 1.00 & $3.64-3.87$ & \\
\hline
\end{tabular}

\section{Discussion}

One of the key measures to control HIV/AIDS epidemic is to provide educational awareness programs to the public, as they advocate maintaining the healthy behaviors in the general public $[15,17,18]$. The present study is the first study in kingdom of Bahrain to determine the attitudes of the general Bahraini public towards HIV/AIDS, which may help in positive contribution to the clarification of the HIV prevention plans and regulation programs in Bahrain.

Negative attitudes towards HIV/AIDS patients were evident among the participants, through avoid shaking hands, sharing meals, or sitting near HIV/AIDS patients, and through thinking that HIV patients should inform their colleagues about their medical condition and believing to isolate them in work areas and schools. Many other studies conducted in several countries showed similar results $[10,19,20]$. Taher and Abdelhai (2011) showed in their study that $75.7 \%$ of the respondents marked uncomfortable feeling if they would work with HIV/AIDS patients in the same office [21]. However, another study showed that $52.3 \%$ of the respondents agreed that HIV/AIDS patients 
deserve having equal rights in study and work as healthy people [22]. Another study also showed that $25 \%$ of participants agreed that HIV/AIDS patients have the right to keep their medical condition confidential [23].

Feelings of anger and lack of sympathy leads to generation of the negative attitudes toward HIV/AIDS patients [24]. In our study, the case was opposite. Although negative attitudes were common, many participants reported their feelings towards HIV patients to be compassionate. This suggests that those negative attitudes are due to feeling of fear from getting infected with the disease, which was conspicuous through the other responses, such as a high proportion of the participants strongly agreed to have HIV test among the regular medical checkup, and many agreed that AIDS could be a threat in the future to Bahraini society. In addition, the strong agreement of a high proportion of the respondents that HIV patients should receive a similar support and respect as other diseases patients is another evidence of the compassionate feeling.

Similar to the results of some studies, $[14,24]$, a big proportion of the participants believed that HIV infection is a divine punishment. In contradictory, studies from USA, Kenya, South Africa and Tanzania didn't show that [25]. Generally, in Islamic countries, the idea that HIV can be a punishment from God is more common, believing that it can be a result of not following the Islamic rules, since the major modes of HIV transmission, such as drug abuse, homosexual behaviors, and sexual relations outside marriage are forbidden in Islam $[18,26]$. In addition, a high proportion of the participants thought that following Islamic rules can reduce the spread of HIV infection. A study suggested that the attitudes towards HIV/AIDS are one of the aspects in life that is controlled by culture and religion [18]. Those findings were expected, as Bahrain society is diverse in terms of ethnic, culture, and religion, with Muslim population of about $99.8 \%$ of the total population [16].

The negative attitudes towards HIV/AIDS patients, whether it was due to feeling of fear, or religious beliefs, or even due to lack of knowledge; it cause stigmatization against those patients, which forms a difficulty in prevention of the disease [19, 24]. Successful prevention programs need to reduce or eliminate the stigmatization, by introducing legislations to reduce HIV/AIDS discrimination, and development of informative campaigns [27-28].

\section{Conclusions}

In conclusion, this study gives a general idea of the Bahraini population's attitudes towards HIV/AIDS. The negative attitudes towards HIV/AIDS patients were the major 
finding of this study. The public health education and awareness campaign need to be revised by the Bahraini authorities in cooperation with the local media and Ministry of Education. Reducing those negative attitudes by such programs is important to step in the control of HIV/AIDS.

\section{Acknowledgement}

The authors would like to thank all participants who performed the survey. Special thanks to Khulood Madad and Fatima Abdulla who contributed in the questionnaire design and data collection.

\section{References}

[1] Fan H, Conner RF, Villarreal LP (2011) AIDS: Science and Society, 6th edition. London: Jones \& Bartlett Publishers $240 \mathrm{p}$.

[2] Kartikeyan S, Bharmal RN, Tiwari RP, Bisen PS (2007) HIV and AIDS: Basic Elements and Priorities. Netherlands: Springer 418 p.

[3] Knipe DM, Howley P (2013) Fields Virology. Wolters Klwer Health/Lippincott Williams \& Wilkins. USA.

[4] Cock KM, Crowley SP, LO Y, Granich RM, Williams BG (2009) Preventing HIV transmission with antiretrovirals. Bulletin of the World Health Organization 87: 488488

[5] UNAIDS (2011) Middle East and North Africa Regional Report on AIDS. Available: http://www.unaids.org/en/media/unaids/contentassets/documents/ unaidspublication/2011/JC2257_UNAIDS-MENA-report-2011_en.pdf Accessed November 2014.

[6] UNGASS Country Progress Report (2014) Available: http://www.unaids.org/sites/ default/files/country/documents//BHR_narrative_report_2014.pdf Accessed November 2014

[7] Islam MT, Mostafa G, Bhuiya AU, Hawkes S, Fransisco A. (2002) Knowledge on, and Attitude Toward, HIV/AIDS among Staff of an International Organization in Bangladesh. J Health Popul Nutr 20: 271-278.

[8] Andsoy II, Gungor T, Sahin A0, Kar G, Ergil P, Inanmaz N (2013) HIV infection and the Turkish people: A cross-sectional study on the perceptions of Safranbolu inhabitants. Acta Medica Mediterranea 29: 603-610. 
[9] Mann JM, Tarantola D, Netter TW (1992) AIDS in the World. USA:Harvard University Press $1037 \mathrm{P}$

[10] Khan MA (2002) Knowledge on AIDS among female adolescents in Bangladesh: Evidence from the Bangladesh demographic and health survey data. J Health Popul Nutr 20: 130-137.

[11] Bin Briek AS (2009) Knowledge and attitudes of prisons in Mukalla City, Republic of Yemen towards HIV/AIDS. Alandalus For Social and Applied Sciences 2: 18-39

[12] Ghabili K, Shja MM, Kamran P (2008) The Iranian female high school students' attitude towards people with HIV/AIDS: a cross-sectional study. AIDS Research and Therapy 5: 1-5

[13] Nur N (2012) Turkish school teachers' knowledge and attitudes toward HIV/AIDS. Croat Med J 53: 271-7

[14] Fraim NL (2012) Knowledge levels and misconceptions about HIV/AIDS: What do University Students in Turkey Really Know? International Journal of Humanities and Social Science 2: 50-58

[15] Torabi MR (2000) Family physicians' knowledge and attitudes and practices regarding HIV/AIDS Prevention. The Health Education Monograph Series 18: 51-58

[16] Ministry of Cabinet Affairs, Kingdom of Bahrain (2010) Basic Results Population, Housing, Buildings and Establishment Census. Available: http://www.cio.gov.bh/ cio_ara/English/Publications/Census/Population/6.pdf Accessed November 2014

[17] Hasani L, Aghamolaei T, Tavafian SS, Sabili A (2010) Knowledge of Iranian nurses about HIV/AIDS: A cross sectional study from Bandar Abbas. Iranian Journal of Clinical Infectious Diseases 5: 161-165

[18] Hasanain M (2005) Cultural Approach to HIV/AIDS Harm Reduction in Muslim Countries. Harm Reduction Journal 2: 23-31

[19] Badahdah AM, Sayem N (2010) HIV-related knowledge and AIDS stigma among college students in Yemen. Eastern Mediterranean Health Journal 16: 901-906

[20] Taher E, Abdelhai R (2011) Nurses' knowledge, perceptions, and attitudes towards HIV/AIDS: Effects of a health education intervention on two nursing groups in Cairo University, Egypt. Journal of Public Health and Epidemiology 3: 144-154

[21] Montazeri A (2005) AIDS knowledge and attitudes in Iran: results from a populationbased survey in Tehran. Patient Educ Couns 57: 199-203

[22] Celik M, Arican O, Celikoz-Ozkan D (2007) Turkish Internet users' awareness of and attitudes toward HIV/AIDS and other STDs. Acta Dermatoven APA 16: 13-20 
[23] Bhosale SB, Jadhav SL, Singru SA, Banerjee A (2010) Behavioral surveillance survey regarding human immunodeficiency virus/acquired immunodeficiency syndrome among high school and junior college students. Indian J Dermatol Ve 76: 33-37

[24] Abolfotouh MA, Al Saleh SA, Mahfouz AA, Abdulfotouh SM, Al Fozan HM (2013) Attitudes of Saudi Nursing Students on AIDS and Predictors of Willingness to Provide Care for Patients in Central Saudi Arabia. SAGE Open 3: 1-11

[25] Wang G, Wada K, Hoshi K, Sasaki N, Ezoe S, Satoh T (2013) Association of Knowledge of HIV and Other Factors with Individuals' Attitudes toward HIV Infection: A National Cross-Sectional Survey among the Japanese Non Medical Working Population. PloS one 8: 1-8

[26] Al-Ghanim SA (2005) Exploring public knowledge and attitudes towards HIV/AIDS in Saudi Arabia: A survey of primary health care users. Saudi Med J 26: 812-818

[27] Ouzouni C, Nakakis K (2012) HIV / AIDS knowledge, attitudes and behaviours of student nurses. Health Science Journal 6: 129-150

[28] Mwamwenda TS (2013) Human immunodeficiency virus/acquired immune deficiency syndrome (HIV/AIDS) as God's directive. Journal of AIDS and HIV Research 5: 366-369

[29] Hassan ZM, Wahsheh MA (2011) Knowledge and Attitudes of Jordanian Nurses towards Patients with HIV/AIDS: Findings from a Nationwide Survey. Issues in Mental Health Nursing 32: 774-784

[30] Fahimi FR (2007) Time to intervene: Preventing the spread of HIV/AIDS in the Middle East and North Africa. Population Reference Bureau Available: http://www.prb.org/ pdfo7/hivaidsinmena.pdf Accessed November 2014.

[31] Mahajan AP, Sayles JN, Patel VA, et al (2008) Stigma in the HIV/AIDS epidemic: A review of the literature and recommendations for the way forward. AIDS 22 Suppl 2:67-79.doi:10.1097/01.aids.0000327438.13291.62 